\title{
Percepção dos Processos de Aprendizagem pelos alunos do curso de Graduação e Pós- graduação da Faculdade de Odontologia de Piracicaba .
}

\author{
Gabriel Wilson*, Fabio Luiz Mialhe (P)
}

\section{Resumo}

O objetivo desta pesquisa foi caracterizar e avaliar os processos de ensino e aprendizagem desenvolvidos na Faculdade de Odontologia de Piracicaba, na perspectiva de estudantes de graduação e pós-graduação. Dois questionários on-line foram desenvolvidos. Para os alunos de graduação, o professor é um fator determinante em seu processo de formação profissional, bem como a estratégia de ensino que utiliza para instruir seus alunos. Para os estudantes de graduação, há um baixo interesse dos professores em relação ao uso de novas estratégias de ensino e aprendizagem diferentes do padrão tradicional das aulas expositivas. Essa perspectiva foi muito semelhante na amostra de alunos de pós-graduação.

\section{Palavras-chave:}

odontologia, ensino, aprendizagem

\section{Introdução}

A avaliação dos processos de ensino-aprendizagem sob a ótica dos educandos é de fundamental importância para a melhoria da formação dos futuros profissionais. No entanto, existem poucos estudos nacionais que avaliaram a percepção, por parte dos alunos dos cursos de Graduação e Pós-graduação em Odontologia, sobre o impacto que as diversas modalidades de ensinoaprendizagem apresentam na sua formação, contribuindo para uma educação mais integral e adequada à realidade e às necessidades do mercado profissional. Desta forma, o presente estudo tem como objetivo avaliar a percepção dos alunos de Graduação e Pós-graduação da Faculdade de Odontologia de Piracicaba sobre como as metodologias tradicionais e inovadoras de ensino-aprendizagem tem refletido de forma positiva ou negativa no seu aprendizado para a imersão no mercado de trabalho e, também, e na formação acadêmica daqueles que se preparam para se tornarem futuros pesquisadores e docentes.

\section{Resultados e Discussão}

Em nível de Graduação, verificou-se, de forma geral, que $70,5 \%$ atribui extrema importância às metodologias de ensino e aos processos de aprendizagem como fatores determinantes na sua formação. Cerca de $73,3 \%$ considera como mais eficaz em termos de aprendizagem e solidificação dos conhecimentos, no contexto das aulas teóricas, aquelas que se pautam principalmente sob demonstrações, o mesmo percentual de alunos considera, no contexto das aulas práticas, que as demonstrações em grupos pequenos de alunos é a estratégia mais eficaz de aprendizagem. Para $65 \%$ dos alunos, a figura do professor é extremamente importante no processo de formação profissional. Além disso, para $67,1 \%$ dos alunos, as estratégias de ensino que o docente utiliza também são de extrema importância como reflexo no contexto de formação profissional. Para $51,4 \%$, os docentes apresentam um interesse relativo em desenvolverem metodologias de ensino diferenciadas para os alunos. Para $70,5 \%$ a proximidade e a qualidade da relação entre aluno e professor também é um ponto de extrema importância para os alunos.
Em nível de Pós-Graduação, observou-se que 62,9\% atribui um grau de extrema importância às metodologias de ensino e aprendizagem no contexto da odontologia. Cerca de $51,4 \%$ concordam plenamente que o uso de novas práticas e inovações dentro das estratégias de ensino, principalmente aquelas que proporcionam maior autonomia do aluno na construção do conhecimento, são fundamentais para possibilitar uma formação profissional diferenciada na área odontológica. Em consonância com as opiniões dos alunos de graduação aulas teóricas demonstrativas $(57,1 \%)$ e aulas práticas com demonstrações em grupos pequenos $(62,9 \%)$ são aquelas que foram consideradas as mais eficazes em termos de aprendizagem e solidificação do conhecimento. Cerca de $54,3 \%$, concorda que o uso de tecnologias e plataformas digitais utilizados como recursos didáticos para o melhor desenvolvimento do processo de aprendizagem são abordagens que podem contribuir de forma positiva para a formação daqueles que serão futuros cirurgiões-dentistas. 62,9\% acreditam que as estratégias de ensino utilizadas pelo professor são de extrema importância no processo de formação profissional. 94,3\% tem pretensão à docência na área da odontologia ou em cursos da área da saúde. Apenas $48,6 \%$ possui algum tipo de formação pedagógica voltada para o ensino em odontologia.

\section{Conclusões}

Conclui-se que tanto os alunos de Graduação como Pós-Graduação da FOP apreciam o uso de outras metodologias de ensino, para além da aula expositiva tradicional, porém, verificam que a Instituição apresenta dificuldades para extrapolar o modelo de ensinoaprendizagem hegemônico, focado na transmissão vertical e no treino de habilidades.

1. Diretrizes Curriculares Nacionais do Curso de Graduação em Odontologia. Brasília, 2002. Disponível em: http://portal.mec.gov.br/cne/arquiv os/ pdf/CES032002.pdf.

2. Rocha JS, Dias GF, Campanha NH, Baldani MH. O uso da aprendizagem baseada em problemas na Odontologia: uma revisão crítica da literatura. Rev ABENO. 2016;16 (1):25-38.

3. Freire $\mathrm{P}$. Pedagogia da autonomia: saberes necessários à prática docente. São Paulo: Paz e Terra.1996. 